\title{
UNSUR EKSTRINSIK DALAM KUMPULAN CERPEN KEREMUNTING “ MALAM INDAH “ KARYA RUS ABRUS
}

\author{
Tengku Muhammad Sum \\ Fakultas Ilmu Budaya, Universitas Lancang Kuning. Indonesia \\ tengkumuhamadsum@gmail.com
}

Naskah diterima: 7 November ; direvisi: 14 November; disetujui: 21 November

\begin{abstract}
Abstrak
Analisis ini membuktikan bahwa dalam kumpulan cerpen keremunting, khususnya dalam cerpen Rus Abrus yang berjudul " Malam Indah ", terdapat tiga unsure ekstrinsik, yaitu unsur social, unsur ekonomi dan unsur pendidikan. Dalam penelitian ini sosok Dullah menjadi barometer baru yang menggandeng masyarakat untuk melihat tiga sisi kehidupan yang berbeda mulai dari sisi social, ekonomi dan pendidikan. Dengan demikian, cerpen "Malam Indah ", memberikan pengaruh kepada masyarakat yang ada di daerah Riau umumnya untuk dapat membentuk suatu sikap yang konstan di dalam menjalani kehidupan ini, terutama dari segi social, ekonomi dan pendidikan.
\end{abstract}

Kata Kunci: Unsur Ekstrinsik, Keremunting, Malam Indah.

\begin{abstract}
This analysis proves that in a collection of Keremunting short stories, especially in the short story of Rus Abrus entitled "Malam Indah", there are three extrinsic elements, namely social elements, economic elements and elements of education. In this study Dullah figure into a new barometer that took the community to see the three sides of different lives ranging from the social, economic and educational. Thus, the short story "Malam Indah", gives influence to society in Riau area generally to be able to form a constant attitude in living this life, especially in social, economy and education.
\end{abstract}

Keywords: Extrinsic Element, Keremunting, Beautiful Night.

\section{Pendahuluan}

Keremunting merupakan kumpulan cerita pendek (cerpen) pengarang Riau. Dalam hal ini penulis akan mengambil satu nama pengarang Riau yaitu Rus Abrus dalam karyanya "Malam Indah", dalam hal ini kita tertarik mengambil karya Rus Abrus karena ada kesesuaian dalam realitas kehidupan masyarakat sehari hari yang ada di masyarakat Indragiri, sekarang itu bernama Kuantan Singingi khususnya dalam factor luar. Faktor luar yang di maksud adalah unsur ekstrinsik. Unsur ekstrinsik merupakan sarana bagi masyarakat untuk mengetahui keadaan luar dari dalam cerita seorang pengarang. Menurut Burhan Nurgiyantoro unsur ekstrinsik adalah unsur yang berada di luar karya fiksi yang mempengaruhi lahirnya karya namun tidak menjadi bagian di dalam karya fiksi itu sendiri. Menurut Kamus Besar Bahasa Indonesia (KBBI) ekstrinsik/eks·trin·sik/ /ékstrinsik/ $a$ berasal dari luar (tentang nilai mata uang, sifat manusia, atau nilai suatu peristiwa); bukan merupakan bagian yang tidak terpisahkan dari sesuatu; tidak termasuk intinya.

Unsur ekstrinsik menjadi modal dalam menggali sisi luar kehidupan umat manusia melalui karya sastra. Karya sastra meliputi puisi, prosa, drama. Dalam prosa sendiri meliputi novel, hikayat, cerita pendek (cerpen) dll. Cerpen masuk ke dalam bagian prosa. Menurut H. B. Jassin Sang Paus Sastra Indonesia beliau Mengatakan bahwa cerpen merupakan sebuah cerita singkat yang harus mempunyai bagian terpenting yaitu perkenalan, pertikaian dan penyelesaian. Cerpen yang merupakan cerita singkat atau pendek namun tetap ia adalah cerita yang memiliki ruh untuk dapat berjalan dalam dunia sastra.

\section{Sinopsis}

Cerita pendek yang berjudul "Malam Indah" menceritakan tentang seorang pemuda 
yang bernama Dullah, ia hidup berpindah dan cari uang pun berpindah, itu semua karena keadaan yang pada masa itu negeri ini masih diserang penjajah.

Berbagai macam pekerjaan ia coba mulai dari menarik bendi, penyadap karet dan lainnya. Alhasil semuanya belum bisa mencukupi kebutuhan keluarganya. Walau ia hidup dalam lingkaran penderitaan ia tidak pernah mau meninggalkan pendidikannya walau usianya sudah terbilang tua. Dullah tetap melanjutkan pendidikannya, baginya pendidikan itu penting. Selain pendidikan, Dullah pun ikut dalam gerakan gerilyawan untuk melawan penjajah, al hasil rumah keluarganya hancur oleh serangan penjajah. Penjajah berhasil masuk ke kampungnya. Air mata pun jatuh bercucuran, akan tetapi apa yang mau ditangisi bukan hanya rumah Dullah yang hancur, rumah tetangganya pun juga hancur.

Akhir hidup yang tak usai, Dullah kembali ke pekerjaan lamanya yaitu menarik bendi, suatu malam ia berkeliling dan mendapatkan penumpang yang tak lain adalah gurunya, malu rasa hati, akhirnya ia tetap membawa gurunya dengan wajah ditutup agar tak kelihatan. Sepanjang jalan ia teringat dengan wanita yang ia cintai yang bernama Minah. Walau ia tak jadi bersanding dengan Minah karena harga karet turun dan Minah pun lari ke lelaki mapan, Dullah tetap menjalani hidupnya. Bendi pun berhendi, Dullah pun mendapat uang dua puluh lima.

\section{Pembahasan}

Dalam pembahasan cerita pendek keremunting khusus " Malam Indah", terdapat 3 unsur ekstrinsik, diantaranya adalah unsur sosial, unsur ekonomi, unsur pendidikan.

\subsection{Unsur Sosial}

Unsur sosial merupakan suatu tindakan perorangan terhadap ruang lingkup keluarga dan masyarakat. Adapun unsur social yang terdapat dalam cerpen "Malam Indah " ada di bawah ini :

"Tapi kusir Dullah cari uang banyak, bukan karena bercita-cita untuk dapat Juita yang manis. Tidak. Baginya ada lagi yang lebih bahagia dari pada itu semua : membantu keluarga. Memang sejak kecilnya ia telah turut aktif menyelenggarakan kebutuhan rumah tangga keluarganya." ( hal. 27 ).

Dari kutipan di atas jelas sikap sosial yang berupa tindakan yang dilakukan oleh
Dullah guna membantu dan turut aktif dalam menyelenggarakan kebutuhan keluarganya.

Bahkan tidak hanya itu unsur sosial juga terlihat jelas dalam kutipan yang ada di bawah ini :

"Waktu revolusi ia baru berumur empat belas tahun. Ia turut menggabungkan diri dengan kesatuan gerilya di kampung. Ia telah turut bertempur di malam hari dan di siang yang terang. Bersama rombongannya ia ikut lari ke hutan waktu pertahanannya dapat ditembus dan daerahnya diduduki. Tapi waktu itu ia yakin bahwa menderita untuk mencapai tujuan yang murni, bahagia akhirnya." ( hal. 27)

Dari kutipan di atas jelas sikap sosial Dullah yang ikut serta dalam gerakan gerilya di kampung guna melawan penjajah. Selain itu Dullah pun sempat membantu adiknya dalam menempuh pendidikan. Sikap sosial itu terlihat dalam kutipan yang di bawah ini :
"Tapi dengan tak diduga-duga harga karet turun dengan mendadak. Kembali rakyat hidup melarat. Termasuk dullah bersama keluarganya. Tapi untunglah adiknya, tanggungan yang terberat, telah duduk di SGA Negeri. Kelanjutan pelajaran adiknya tak jadi buah pikirannya lagi. Tak perlu dikuatirkan karena ada ikatan dinas yang memberi uang tunjangan tiap bulan. Dan ia tahu adiknya rajin." ( hal. 29)

Sikap sosial Dullah terhadap adiknya sangatlah mulia. Dullah tulus dalam membantu keluarganya. Kini adiknya sudah duduk di SGA dan mendapat biaya dari ikatan dinasnya. Secara otomatis beban Dullah pun berkurang.

\subsection{Unsur Ekonomi}

Unsur ekonomi yang terdapat dalam cerpen tersebut cukup banyak karena cerita ataupun kisahnya menggambarkan kehidupan yang sulit dengan ekonomi terutama uang. Adapun unsur ekonomi yang terdapat dalam tersebut ada di bawah ini:

“DIHITUNG PENDAPATANNYA BARU tujuh rupiah. Ia belum puas dengan uang yang sebanyak itu. Diputarnya bendinya menuju pusat kota kembali." ( hal. 25 ). 
Dari kutipan di atas jelas Dullah sangat sulit dengan ekonominya. Dullah harus extra keras dalam mencari uang.

Selain itu Dullah pun harus berupaya keras mencari uang demi keluarganya, hal ini terbukti dari kutipan yang ada di bawah ini :

“Tapi kusir Dullah cari uang banyak, bukan karena bercita-cita untuk dapat juita yang manis. Tidak. Baginya ada lagi yang lebih bahagia dari pada itu semua : membantu keluarga. Memang sejak kecilnya ia telah turut aktif menyelenggarakan kebutuhan rumah tangga keluarganya." ( hal. 27 ).

Membantu keluarga sudah menjadi hal yang bersifat wajib bagi Dullah, demi keutuhan keluarga. Uang sudah menjadi suatu hal yang sifatnya penting dalam perekonomian pada zamannya, dari itu Dullah tidak peduli dengan resiko pekerjaan yang penting kebutuhan ekonomi keluarga tercukupi.

Perekonomian merupakan hal penting dalam kehidupan umat manusia di zaman kontemporer, dalam hal ini tergambar dari kehidupan Dullah yang sangat gigih dalam mencari uang. Uang sudah seperti menjadi nyawa bagi manusia seperti kutipan yang ada di bawah ini :

“ Di simpang yang ramai Dullah tak pernah lupa melakukan aturanaturanyang perlu, membunyikan bel, menunjuk arah tujuan jalan yang akan ditempuhnya, dan ia hati-hati sekali mengekang kudanya. Ini perlu. Ia mesti hati-hati dan sekali-kali ia tak merasa hina menjalankan peraturan-peraturan lalulintas itu dengan dengan patuh dan jujur. Pelanggaran amat dihindarkannya. Ia tak mau namanya jadi buruk di mata masyarakat dan yang penting sekali . . . di mata majikannya yang suka memecat para pekerjanya. Ia belum mau dipecat. Ia takut kehilangan pekerjaannya. Sebab itu ia harus menjaga nama supaya jangan buruk dan supaya mudah mencari uang. Ia belum mau mati, ia masih ingin hidup terus dan untuk itu perlu sekali uang. Sekali lagi uang. Uang. Seolah-olah uang saja yang menghidupkan manusia. Seolah-olah uanglah yang memelihara manusia di dunia ini. Ia akui uang berkuasa atas diri manusia. Dan orang yang banyak uangnya kuat. Segala keinginanya akan terpenuhi dengan lancar." ( hal. 27 ).

Dari kutipan di atas jelas ekonomi yang berupa uang merupakan persoalan yang terus bergulir dalam kehidupan san tokoh yang bernama Dullah.

Faktor ekonomi merupakan kendala yang cukup membebani si tokoh, namun ia tetap berusaha menjalani hidupnya dengan semangat. Tak peduli malam ia tetap berusaha mencari uang walau hasilnya minim. Menarik bendi merupakan cara Dullah untuk mendapatkan uang. Kerja kerasnya dibuktikan pada kutipan yang ada di bawah ini :

" - Berhenti di sini saja - kata si gadis. Ia berhenti di muka gedung mentereng. Tapi lama sesudah bendi berhenti, keduanya belum juga turun. Rupanya itulah saat perpaduan bibir dan hati yang penghabisan pada malam itu.

- Berapa ? - tanya yang laki-laki. Dullah berpikir, inilah kesempatan itu.

- Dua puluh lima - katanya tegas.

- Aduh mahalnya, tukas si gadis.

- Ah, biar. Tak apa. Tak apa - kata si pemuda.

Malam indah berakhir dengan happy end bagi mereka dengan nikmat asmara, dan happy end bagi Dullah dengan uang dua puluh lima rupiah." ( hal. 31-32 ).

Dari kutipan di atas Dullah secara nyata berusaha keras mendapat uang walau harus sedikit menaikkan harga.

Tidak hanya itu Dullah pun berusaha mencari uang dengan cara menjadi penyadap karet. Terbukti dari kutipan yang ada di bawah ini :

“ Ia jadi penyadap karet. Harga karet waktu itu sedang di atas. Para empunya kebun karet bahagia dan mewah. Kadang-kadang tampak berlebih-lebihan amat. Begitupun Dullah dan keluarganya dapat bahagia pula ala kadarnya." ( hal. 28 ). 
Dari kutipan yang ada di atas jelas terbukti usaha dari Dullah yang tak kenal kata menyerah demi memenuhi kebutuhan keluarganya.

Mencari uang merupakan suatu kewajiban bagi setiap umat. Akan tetapi kesusahan merupakan proses hidup yang harus dijalani dengan sabar dan ikhlas. Ketika perekonomian mengalami penurunan maka akan mengakibatkan kesusahan. Hal itulah yang dialami oleh Dullah ketika harga karet turun. Dullah dan keluarganya harus merasakan pahitnya hidup.

Hal itu dibuktikan dalam kutipan yang ada di bawah ini :

" Tapi dengan tak diduga-duga harga karet turun dengan mendadak. Kembali rakyat hidup melarat. Termasuk dullah bersama keluarganya. Tapi untunglah adiknya, tanggungan yang terberat, telah duduk di SGA Negeri. Kelanjutan pelajaran adiknya tak jadi buah pikirannya lagi. Tak perlu dikuatirkan karena ada ikatan dinas yang memberi uang tunjangan tiap bulan. Dan ia tahu adiknya rajin." ( hal. 29)

Dari kutipan di atas jelas telah terjadi peristiwa yang menyakitkan yaitu turunnya harga karet yang membuat para penyadap karet harus gigit jari karena mereka tidak mendapatkan hasil yang maksimal.

Selain itu orang tua Dullah pun sudah jatuh miskin sejak revolusi, jadi tak ada yang dapat orangtuanya beri pada anaknya. Hal itu dapat dilihat pada kutipan yang ada di bawah ini

" Ia tak mau jadi tentara. Ia merasa tugasnya telah selesai mempertahankan kemerdekaan. Ia ingin meneruskan pelajarannya. Sebelum agresi ke-2 ia telah menduduki tingkat ke-2 di SMP. Sedang asyiknya ia belajar, datang perang. Sekolahnya ditutup dan ia pulang ke kampungnya. Kendaraan masa itu tak ada. Apalagi karena jalanjalan banyak yang dirusakkan. Ia terpaksa pulang jalan kaki menempuh jarak lebih dari $200 \mathrm{Km}$ dari kota tempat ia belajar sampai ke kampungnya. Tapi sesudah agresi ke-2 sekolah itu tak buka lagi, gedungnya telah hancur akibat keganasan revolusi. Ia tak dapat meneruskan. Orangtuanya pun sudah tak sanggup pula untuk mengongkosi. Mereka telah jatuh miskin sejak revolusi. "( hal. 27-28)

\subsection{Unsur Pendidikan}

Unsur pendidikan merupakan jembatan dalam menentukan tingkat taraf hidup manusia di zaman kekinian. Pendidikan sudah menjadi barometer guna memberi nilai bagus tersendiri bagi siapa saja yang memiliki pendidikan yang mumpuni.

Dalam cerpen " Malam Indah “ pendidikan menjadi hal penting dan harus tetap diperjuangkan terbukti dari kutipan yang ada di bawah ini :

“ Beberapa bulan kemudian ia telah jadi kusir bendi di Kota Padang. Pagi ia bersekolah. Ia melanjutkan pelajarannya di SMP. Ia tak merasa hina dan malu -- karena ia menganggap tak ada gunanya - duduk sebangku dengan anak-anak yang berumur 14 atau 13 tahun. Semua teman-teman hormat kepadanya. Guru-guru segan kepadanya. Umurnya telah 21 dan ia mengulang di kelas dua. Ia bercita-cita sesudah SMP akan ke SGA. Ia ingin jadi guru di daerahnya, agar mereka jangan hidup tergantung kepada karet belaka." ( hal. 29-30).

Dari kutipan di atas jelas tokoh yang bernama Dullah sangat mementingkan pendidikan walau usia telah terbilang tua. Namun tekad dan semangatnya mengubur rasa malu kepada teman dan gurunya.

Semangat dan tekad sang tokoh dalam mengejar pendidikannya terbukti dari kutipan yang ada di bawah ini :

“ Ia tak mau jadi tentara. Ia merasa tugasnya telah selesai mempertahankan kemerdekaan. Ia ingin meneruskan pelajarannya. Sebelum agresi ke-2 ia telah menduduki tingkat ke-2 di SMP. Sedang asyiknya ia belajar, datang perang. Sekolahnya ditutup dan ia pulang ke kampungnya. Kendaraan masa itu tak ada. Apalagi karena jalanjalan banyak yang dirusakkan. Ia terpaksa pulang jalan kaki menempuh jarak lebih dari $200 \mathrm{Km}$ dari kota tempat ia belajar sampai ke 
kampungnya. Tapi sesudah agresi ke-2 sekolah itu tak buka lagi, gedungnya telah hancur akibat keganasan revolusi. Ia tak dapat meneruskan. Orangtuanya pun sudah tak sanggup pula untuk mengongkosi. Mereka telah jatuh miskin sejak revolusi. "( hal. 27-28)

Tidak hanya sang tokoh Dullah yang sangat mementingkan pendidikan, adiknya pun terus mengejar pendidikan. Terbukti dari kutipan yang ada di bawah ini :

“ Tapi dengan tak diduga-duga harga karet turun dengan mendadak. Kembali rakyat hidup melarat. Termasuk dullah bersama keluarganya. Tapi untunglah adiknya, tanggungan yang terberat, telah duduk di SGA Negeri. Kelanjutan pelajaran adiknya tak jadi buah pikirannya lagi. Tak perlu dikuatirkan karena ada ikatan dinas yang memberi uang tunjangan tiap bulan. Dan ia tahu adiknya rajin." ( hal. 29)

Dari kutipan di atas jelas terbukti bahwa adik Dullah sangat gigih dalam menjalani jenjang demi jenjang pendidikan yang ia tempuh dengan sungguh-sungguh.

Dullah yang berilmu sedikit tetap mengaplikasikan ilmunya di mana pun ia berada, termasuk di jalan raya. Dullah tetap mematuhi aturan lalu lintas dengan baik dan benar.

Dullah jujur dalam berkendara. Ia taati rambu-rambu yang ada. Semua itu ia lakukan karena ia memiliki ilmu walau sedikit. ilmu yang sedikit itu yang gunakan untuk keselamatannya dan untuk menjaga nama baiknya. bawah ini :

Hal itu terbukti dari kutipan yang ada di

“ Di simpang yang ramai Dullah tak pernah lupa melakukan aturanaturanyang perlu, membunyikan bel, menunjuk arah tujuan jalan yang akan ditempuhnya, dan ia hati-hati sekali mengekang kudanya. Ini perlu. Ia mesti hati-hati dan sekali-kali ia tak merasa hina menjalankan peraturan-peraturan lalulintas itu dengan dengan patuh dan jujur. Pelanggaran amat dihindarkannya. Ia tak mau namanya jadi buruk di mata masyarakat dan yang penting sekali . . . di mata majikannya yang suka memecat para pekerjanya. Ia belum mau dipecat. Ia takut kehilangan pekerjaannya. Sebab itu ia harus menjaga nama supaya jangan buruk dan supaya mudah mencari uang. Ia belum mau mati, ia masih ingin hidup terus dan untuk itu perlu sekali uang. Sekali lagi uang. Uang. Seolah-olah uang saja yang menghidupkan manusia. Seolah-olah uanglah yang memelihara manusia di dunia ini. Ia akui uang berkuasa atas diri manusia. Dan orang yang banyak uangnya kuat. Segala keinginanya akan terpenuhi dengan lancar." ( hal. 27 ).

Dullah sangat patuh terhadap aturan yang ada. Kutipan yang ada di atas merupakan buktu bahwa Dullah memiliki suatu sikap yang sudah memiliki dasar keilmuan.

Tidak hanya itu unsur pendidikan pun terlihat dengan jelas dalam kutipan yang ada di bawah ini :

" Waktu revolusi ia baru berumur empat belas tahun. Ia turut menggabungkan diri dengan kesatuan gerilya di kampung. Ia telah turut bertempur di malam hari dan di siang yang terang. Bersama rombongannya ia ikut lari ke hutan waktu pertahanannya dapat ditembus dan daerahnya diduduki. Tapi waktu itu ia yakin bahwa menderita untuk mencapai tujuan yang murni, bahagia akhirnya." ( hal. 27)

Dari kutipan yang ada di atas jelas terlihat bagaimana Dullah sangat ingin masuk ke kelompok gerilyawan yang ada di kampungnya, untuk mendapatkan ilmu perang. Dalam perang pun harus ada ilmunya. Ilmu tersebut ia dapat dalam proses latihan dalam gerilyawan yang ada di kampungnya. Semua itu demi kemerdekaan untuk tanah air.

\section{Kesimpulan}

Dalam cerpen yang berjudul "Malam Indah, ternyata terdapat unsur ekstrinsik, seperti unsur sosial, unsur ekonomi dan unsur pendidikan. Dalam hal ini membuktikan bahwa cerita pendek (cerpen) “ Malam Indah ” karya Rus Abrus memiliki nilai atau mutu yang baik untuk dapat menjadi barometer bagi kehidupan masyarakat sebagai renungan untuk muhasabah diri. 


\section{Daftar Pustaka}

Hamidy, UU. 2001. Pembahasan Karya Fiksi dan Puisi. Pekanbaru : Unri Press

Heryanto, Ariel. 1985. Perdebatan Sastra Kontekstual. Jakarta : CV. Rajawali

J. Waluyo, Herman. 2003. Apresiasi Puisi untuk Pelajar dan Mahasiswa. Jakarta : PT. Gramedia Pustaka Utama

Nurgiyantoro, Burhan. 2007. Teori Pengkajian Fiksi. (Edisi 7). Yogyakarta : Gadjah Mada University Press.

Pe Amarinza, Ediruslan. Junus, Hasan. Abrus, Rus. Bachri Judin, Syamsul. Mahyudin.
1989. Kumpulan Cerpen Keremunting.Pekanbaru : Gramitra

Semi, M. Atar. 1988. Anatomi Sastra. Padang : Angkasa Raya

Sugono, Dr. Dendy. 2005. Kamus Besar Bahasa Indonesia. (Edisi Baru.) Jakarta : Balai Pustaka

Teeuw, A. 1989. Sastra Indonesia Modern II. Jakarta : Pustaka Jaya 